\title{
Unusual infections complicating the use of steroids with severe alcoholic hepatitis: Report of two cases
}

\author{
Vitor ARAntes bSC, PinA Michieletti MD FRCPC, ROsS CAMERON MD FRCPC, JeNNy HEATHCOTE MD FRCPC, \\ MORRIS SHERMAN MD PHD FRCPC
}

V Arantes, P Michieletti, R Cameron, J Heathcote, M Sherman. Unusual infections complicating the use of steroids with severe alcoholic hepatitis: Report of two cases. Can J Gastroenterol 1995;9(2):81-84. Corticosteroid therapy for acute alcoholic hepatitis has been demonstrated to enhance survival in patients who are encephalopathic, and who do not have renal failure or gastrointestinal bleeding. However, the complications of steroid therapy in such patients have been less well documented. The authors report two patients with alcoholic liver disease who developed life-threatening infections after steroid therapy was started. The first patient initially developed diabetes followed by Fournier's gangrene of the perineum, and a lung abscess following septic emboli. The second patient had established alcoholic cirrhosis rather than alcoholic hepatitis. She developed a necrotic ulcer on the arm at the site of an intravenous line, which was infected with a rhizopus species. Despite surgical debridement the lesion progressed and contributed to her death. Treatment of alcoholic hepatitis with steroids is not innocuous, and physicians should be aware of the potential for life-threatening complications.

Key Words: Alcoholic hepatitis, Diabetes, Fournier's gangrene, Rhizopos, Steroid therapy

Infections inhabituelles compliquant le recours à la corticothérapie dans l'hépatite alcoolique grave : deux rapports de cas

RÉSUMÉ : La corticothérapie dans l'hépatite alcoolique aiguë s'est révélée apte à améliorer le taux de survie chez les patients qui souffrent d'encéphalopathie, mais qui n'ont aucune insuffisance rénale ni hémorragie digestive. Toutefois, les complications de la corticothérapie chez de tels patients ont moins bien été documentées. Les auteurs font état de deux cas de maladie hépatique alcoolique qui ont développé des infections gravissimes après le début de la corticothérapie. Le premier patient a d'abord développé un diabète, suivi d'une gangrène de Fournier

voir page suivante

Faculty of Medicine, Universidade Federal de Minas Gerais, Belo Horizonte, Brazil; and Departments of Medicine and Pathology, Faculty of Medicine, University of Toronto and the Toronto Hospital, Toronto, Ontario

Correspondence: Dr Morris Sherman, The Toronto Hospital, General Division, Eaton North, 9-223, 200 Elizabeth Street, Toronto, Ontario M5G 2C4. Telephone (416) 340-4756

Received for publication April 21, 1994. Accepted October 28, 1994 $\triangle$ lcoholic hepatitis is aN Lacute, severe form of alcoholic liver disease with high mortality, ranging from 4 to $65 \%$ (1). Therapy includes abstinence, treatment of ascites and hepatic encephalopathy, and a search for recent bleeding or infection (2). Corticosteroid therapy has been used to reduce hepatic inflammation and collagen formation, stimulate hepatocyte regeneration and interrupt immune-mediated hepatic injury $(1,3)$. Several randomized trials of corticosteroid therapy in alcoholic hepatitis have been published with variable results $(4,5)$. However, a recent metaanalysis and the most recently reported trial have shown higher survival rates in steroid-treated subjects with severe alcoholic hepatitis than in controls $(6,7)$.

The use of steroids is associated with several important side effects including the precipitation of diabetes and infection (8). In this paper we report two patients with alcoholic liver disease who developed serious unusual infections after the introduction of therapy with steroids.

\section{CASE ONE}

A 46-year-old man presented with a 15-year history of alcohol abuse, drinking at least $100 \mathrm{~g} /$ day in the previous year. One week before admission he be- 
au niveau du périnée et un abcès pulmonaire après une embolie septique. La deuxième patiente présentait une cirrhose alcoolique avérée plutôt qu'une hépatite alcoolique. Elle a développé un ulcère nécrotique au bras, au point d'insertion d'une intraveineuse, infecté au rhizopus. Malgré un débridement chirurgical, la lésion a progressé et la patiente est décédée. Le traitement de l'hépatite alcoolique à l'aide de corticostéroïdes n'est pas sans danger et les médecins doivent être conscients d'un risque de complications à potentiel fatal.

came progressively jaundiced. On admission to another hospital total bilirubin was $499 \mu \mathrm{M} / \mathrm{L}$ (normal less than 20), aspartate aminotransferase (AST) was $191 \mathrm{U} / \mathrm{L}$ (normal less than 40), alkaline phosphatase was $275 \mathrm{U} / \mathrm{L}$ (normal less than 110) and prothrombin time (PT) was $15.0 \mathrm{~s}$ (control 12.0). He was not a known diabetic but blood glucose at admission was $9.1 \mathrm{mM} / \mathrm{L}$ (normal range 4.0 to 6.0 ). Alcoholic hepatitis was diagnosed clinically and treatment was started with prednisone $50 \mathrm{mg} /$ day.

After two weeks without improvement the patient was transferred to The Toronto Hospital. Diagnosis was confirmed by transjugular liver biopsy that demonstrated severe steatohepatitis, cholestasis and cirrhosis (Figure 1), with a corrected sinusoidal pressure of $22 \mathrm{mmHg}$ (normal less than 5). The discriminant function (2) was 53.5. Prednisone was stopped and methylprednisolone $36 \mathrm{mg} /$ day was started. Ascites was treated with a salt-free diet, diuretics and paracentesis. The patient slowly improved and was discharged 20 days later on a tapering dose of methylprednisolone.

Two weeks after discharge the patient was readmitted with progressive weakness, moderate ascites, jaundice (total bilirubin $154 \mu \mathrm{M} / \mathrm{L}$ ), nonketotic hyperglycemia (blood glucose 26.7 $\mathrm{mM} / \mathrm{L}$ ) and left ear otitis externa. He was treated with diuretics, intravenous insulin, topical polymyxin B and amoxycillin/clavulanic acid. Paracentesis revealed no evidence of spontaneous bacterial peritonitis. Methylprednisolone was tapered gradually and discontinued.

Seven days after admission, the patient complained of a pustule on the right buttock. The following day it had doubled in size, and was incised and drained. Forty-eight hours later, the patient complained of severe perianal pain and fever $\left(38.5^{\circ} \mathrm{C}\right)$, and had developed a leukocytosis (23.0 billion/ L, normal 4.0 to 11.0 ). A large necrotic area in the perianal region was noted. He was treated with clindamycin and cefotaxime, and local debridement was performed. In spite of this the necrotic area enlarged, encompassing most of the right buttock and perineum, consistent with Fournier's gangrene. Extensive surgical debridement was required. The patient gradually improved but complained of persistent cough. Repeat chest $\mathrm{x}$-ray showed a right upper lobe abscess; it was thought to be related to septic emboli and was successfully treated with antibiotics. Thirty-five days after admission he was discharged with the buttock lesion healing well. Blood sugar was controlled, chest $\mathrm{x}$-ray was normal and the serum liver biochemistry was improving.

\section{CASE TWO}

A 57-year-old woman presented with a 20-year history of alcohol abuse (120 g/day). She had developed bleeding esophageal varices resistant to sclerotherapy, and underwent a distal splenorenal shunt in the year before admission. A liver biopsy at that time showed micronodular cirrhosis with steatosis and mild inflammatory activity consistent with alcoholic liver disease (Figure 2). Mild glucose intolerance was noted, but treatment was not required.

Two weeks before this admission she was admitted to a peripheral hospital deeply jaundiced and semiconscious. No history was obtainable. PT was $15.0 \mathrm{~s}$, total bilirubin was 374 $\mu \mathrm{M} / \mathrm{L}$, AST was $55 \mathrm{U} / \mathrm{L}$, blood glucose was $9.5 \mathrm{mM} / \mathrm{L}$ and creatinine was 179 $\mu \mathrm{M} / \mathrm{L}$ (normal 70 to 120 ). A clinical diagnosis of alcoholic hepatitis was made. The discriminant function was 35.8 , and she was treated with supportive care and methylprednisolone 30 $\mathrm{mg} /$ day. Two weeks later her condition was unchanged and she was transferred to The Toronto Hospital.

On admission she was comatose with asterixis, fever, jaundice and moderate ascites. There was an infected necrotic ulcer on the left forearm, related to a previous venous infusion site, which was $3 \times 4 \mathrm{~cm}$ in size. PT was $20.6 \mathrm{~s}$, total bilirubin was $414 \mu \mathrm{M} / \mathrm{L}$, creatinine was $274 \mu \mathrm{M} / \mathrm{L}$ and blood glucose was $9.1 \mathrm{mM} / \mathrm{L}$. A transjugular biopsy was performed. The corrected sinusoidal pressure was $29 \mathrm{mmHg}$. Histology showed findings suggestive of alcoholic cirrhosis without evidence of alcoholic hepatitis. There was marked cholestasis, thought to be related to sepsis. Steroids were discontinued and supportive measures instituted, including debridement of the necrotizing cellulitis and antibiotic therapy (clindamycin and cefotaxime). Biopsy and cultures from the left forearm were positive for combined fungal (rhizopus species) and bacterial (Proteus mirabilis and Staphylococcus aureus) infection. The necrotic area enlarged to $12 \times 8 \mathrm{~cm}$ despite debridement. Amphotericin B was added and surgical debridement repeated. Amputation was considered, but the family refused permission. The patient's liver and renal function worsened and she died one week after admission.

\section{DISCUSSION}

Alcoholic hepatitis is characterized by acute inflammation of the liver, including polymorphonuclear cell infiltration and hepatocyte swelling, hepatocellular necrosis, alcoholic hyalin and collagen deposition, which frequently progresses to established fibrosis and cirrhosis. The role of steroid therapy in alcoholic hepatitis is based on its anti-inflammatory and antifibrotic properties, as well as suppression of immunological processes that may be important in the initiation and perpetuation of injury $(1,2,9)$.

Unusual infections and precipitation of glucose intolerance are well- 


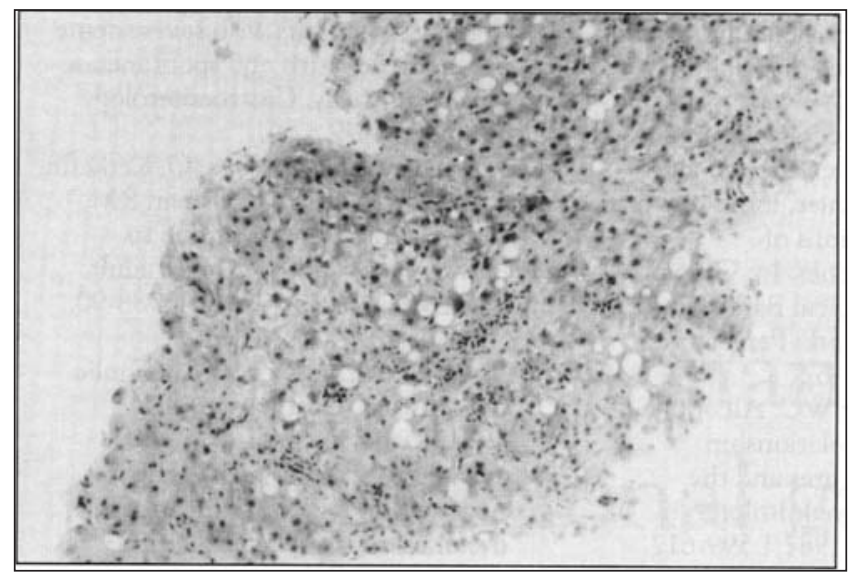

Figure 1) Photomicrograph of a transjugular liver biopsy from case 1 showing steatosis, polymorphonuclear cell infiltration and fibrosis. The appearances are consistent with alcoholic hepatitis (original magnification $\mathrm{x} 50)$

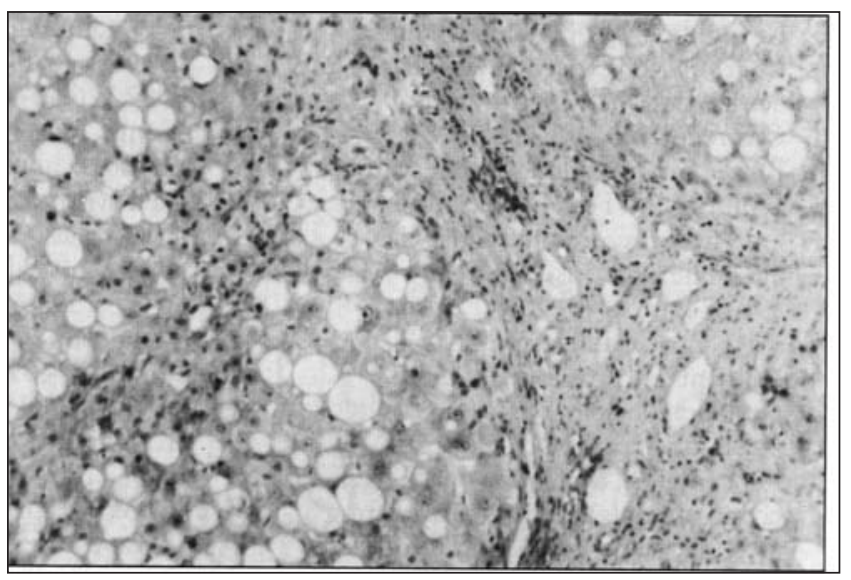

Figure 2) Photomicrograph of a transjugular liver biopsy from case 2 showing steatosis and fibrosis but no acute inflammatory cell infiltrate (original magnification $\times 50$ ). The lack of polymorphonuclear cell infiltrate, necrosis or alcoholic hyaline suggests that acute alcoholic hepatitis is not present known side effects of the general use of steroids (13). In this report, both patients developed severe unusual infections after the introduction of corticosteroid treatment. In both patients alcoholic liver disease was present on a background of diabetes mellitus. The first patient had a clinical diagnosis of alcoholic hepatitis confirmed by liver biopsy that also showed findings suggestive of underlying alcoholic cirrhosis. The patient initially responded well to the methylprednisolone, but three weeks after discharge returned to hospital with moderately severe diabetes and several infections, including otitis externa, Fournier's gangrene and a lung abscess. Fortunately he recovered with antibiotic therapy, surgical measures and a progressive taper in methylprednisolone dose.

The second patient presented with a syndrome of jaundice and hepatic encephalopathy, and a clinical diagnosis of alcoholic hepatitis was made. There was a history of glucose intolerance. The liver biopsy did not confirm alcoholic hepatitis; rather, the findings were suggestive of alcoholic cirrhosis, with superimposed cholestasis due to sepsis. The patient developed a necrotizing cellulitis of the left forearm at the site of a previous intravenous line. The cultures were positive for mixed bacterial and fungal infection. Her condition worsened progressively, and she died of septicemia, and liver and renal failure.

Patients with alcoholic hepatitis are recognized as having an increased risk of severe bacterial infections (3). In patients treated with corticosteroids this risk seems to be further increased. Blitzer et al (4) reported an increased risk of infection associated with steroid therapy in alcoholic hepatitis. In their series 12 patients were treated with steroids. Two died of bacterial peritonitis and two had fungal infections. Two survivors developed oral candidiasis. Depew et al (10) evaluated the efficacy of prednisolone treatment in severe acute alcoholic hepatitis with spontaneous hepatic encephalopathy; they found no difference in mortality between the treated and control groups, but in the treated group the incidence of septic complications was $66 \%$. These included urinary tract infections (fungal and bacterial), septicemia and a perinephric abscess. Stephens and colleagues (11) reported multiple infections in a patient with alcoholic hepatitis and underlying cirrhosis treated with steroids. The patient developed candidal esophagitis, urinary tract infection and spontaneous bacterial peritonitis. The authors suggested that there was a possible interaction between alcoholic cirrhosis and corticosteroid therapy, leading to decreased immunocompetence, and an increased risk of unusual infections.
The effects of corticosteroids on the immune system have been well documented. These include an inhibitory influence on the recruitment and function of leukocytes, monophages/macrophages and natural killer lymphocytes (8). Alcohol is known to impair mobilization and chemotaxis of polymorphonuclear leukocytes, and to decrease adherence and phagocytosis (12). The increased susceptibility to infection in diabetes mellitus is also well recognized but the mechanism is not well established. Neutrophils in diabetics have abnormal adherence, chemotaxis, mobilization, phagocytosis and antimicrobial activity (13).

The combination of diabetes, alcoholic liver disease and steroid therapy is likely to enhance greatly the susceptibility to infection in patients such as those described here. Patients with co-existing alcoholic hepatitis and diabetes mellitus who are treated with steroids are likely at significant risk of severe bacterial and fungal infections, and these patients should be carefully evaluated before deciding therapy; if therapy with steroids is undertaken, these patients require close monitoring.

\section{REFERENCES}

1. Maddrey WC. Alcoholic hepatitis: pathogenesis and approach to treatment. Scand J Gastroenterol 1990;Suppl 175:118-30. 
2. Sherlock S. Diseases of the Liver and Biliary System, 9th edn. Cambridge: Blackwell Scientific Publications, 1993:370-89.

3. Reynolds TB, Benhamou JP, Blake J, Naccarato R, Orrego H. Treatment of acute alcoholic hepatitis.

Gastroenterology 1989;2:208-16.

4. Blitzer BL, Mutchnik MG, Joswi PW, Phillips MM, Fessel JM, Conn Ho. Adrenocorticosteroid therapy in alcoholic hepatitis. Am J Dig Dis 1977;22:477-84.

5. Theodossi A, Eddleston ALWF, Williams R. Controlled trial of methylprednisolone in severe acute alcoholic hepatitis. Gut 1982;23:75-9.

6. Imperiale TF, McCullough AJ. Do corticosteroids reduce mortality from alcoholic hepatitis. Ann Intern Med 1990;113:299-307.
7. Raymond MJ, Poynard T, Rueer B, et al. Randomized trial of prednisolone in patients with severe alcoholic hepatitis. N Engl J Med 1992:326:507-12.

8. Haynes RC Jr. Adrenocorticotropic hormone; adrenocortical steroid and their synthetic analogues, inhibitors of the synthesis and actions of adrenocortical hormones. In: Gilman AG, ed. Pharmacological Basis of Therapeutics. New York: Pergamon Press, Inc, 1991:1431-62.

9. Biotnoff JK, Maddrey WC. Alcoholic liver disease: I. Interrelationship among histologic features and the histologic effects of prednisolone therapy. Hepatology 1981;1:599-612.

10. Depew W, Boyer T, Omata M, Redeker A, Reynolds TB. Double- blind controlled trial of prednisolone therapy in patients with severe acute alcoholic hepatitis and spontaneous encephalopathy. Gastroenterology 1980;78:524-9.

11. Stephens CG, Meadows JG, Kerkefing TM, Markowitz SW, Nisman RM. Spontaneous peritonitis due to Haemophilus influenzae in an adult. Gastroenterology 1979;77:1088-90.

12. Zetterman RK, Sorrel MF. Immunological aspects of alcoholic liver disease. Gastroenterology 1981;81:616-24.

13. Andersen B, Goldsmith GH, Spagnuolo PJ. Neutrophil adhesive dysfunction in diabetes mellitus: the role of cellular and plasma factors. J Lab Clin Med 1988;111:275-85. 


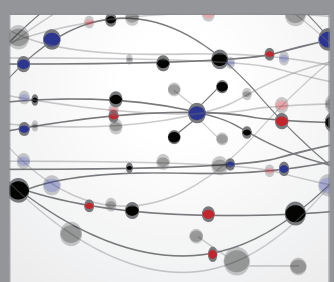

The Scientific World Journal
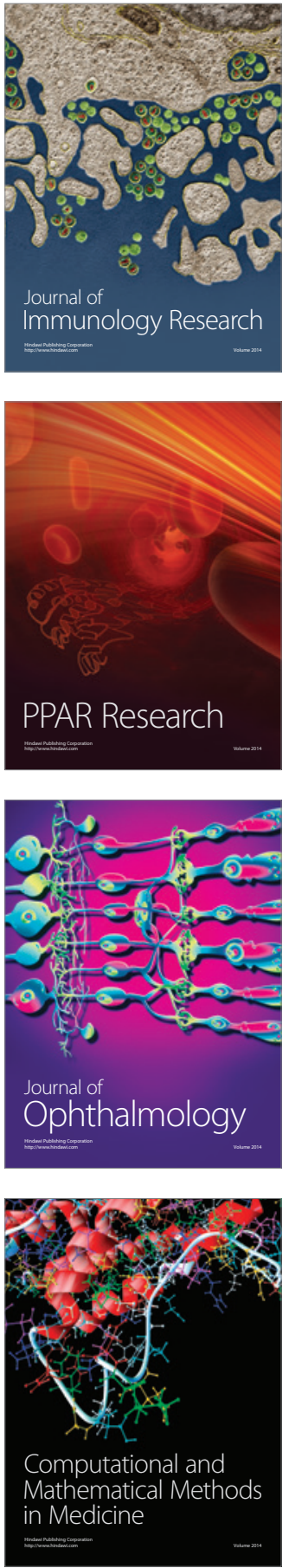

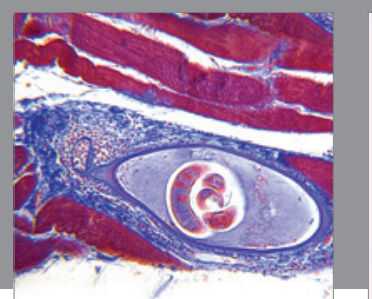

Gastroenterology Research and Practice

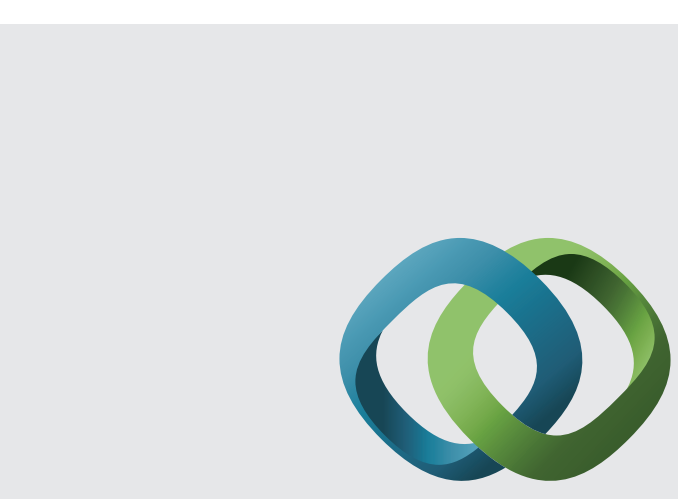

\section{Hindawi}

Submit your manuscripts at

http://www.hindawi.com
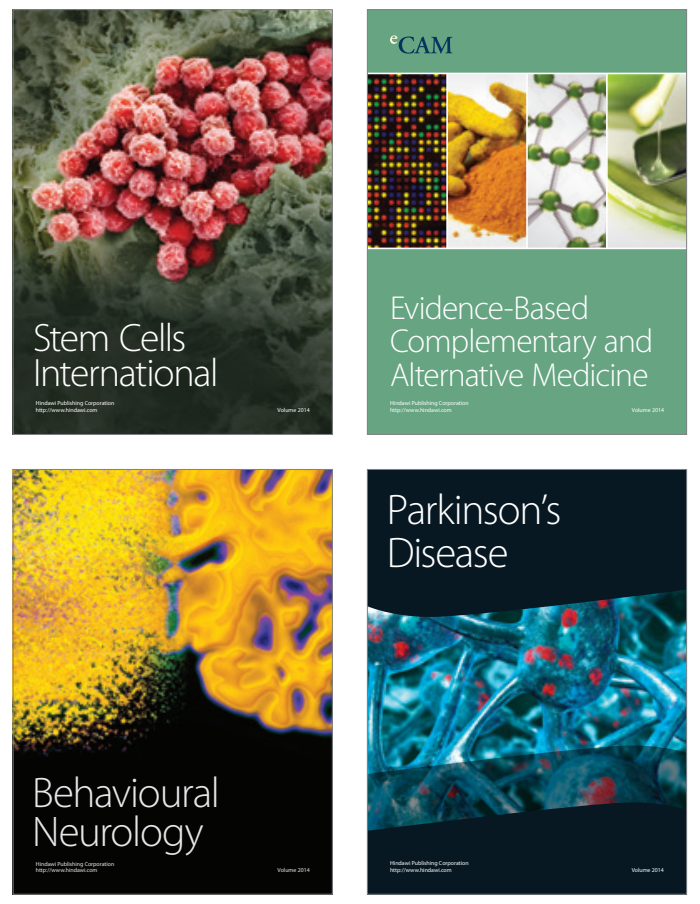
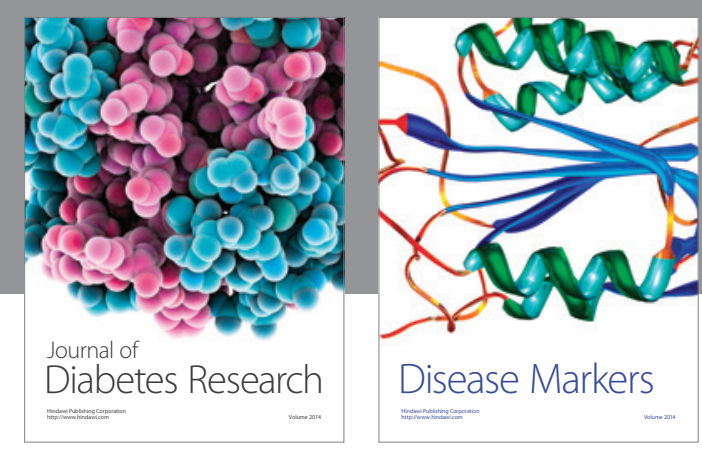

Disease Markers
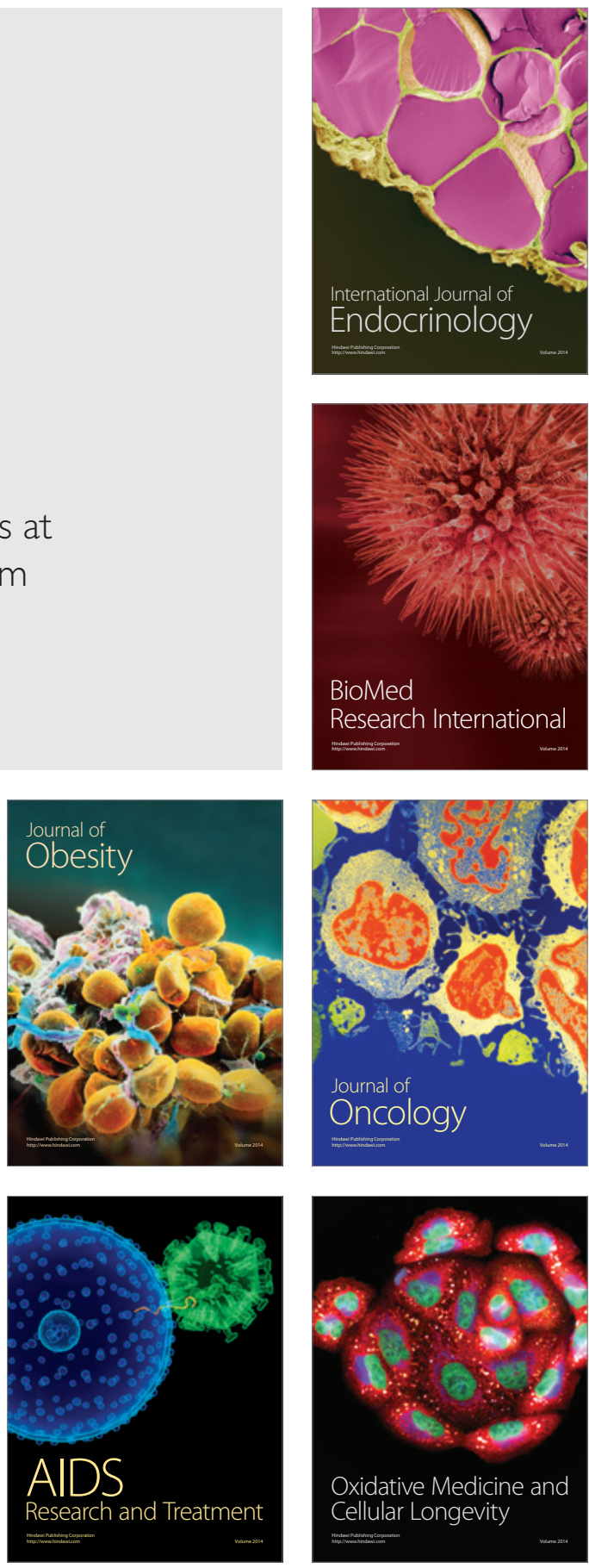